\title{
The long-term share price reaction to Black Economic Empowerment announcements on the JSE
}

\begin{abstract}
Black Economic Empowerment has been one of the South African government's primary mechanisms for addressing the economic imbalances of the apartheid era. Voluntary sector "charters", and more recently legislation, have required largely white owned business enterprises to become more inclusive across key areas of economic empowerment, including the provision of minimum levels of ownership for black shareholders.

This research employs event study methodology to examine the long-term impact on the share prices of listed companies after announcements are made relating to black empowerment deals which impact equity ownership. The research examines 118 announcements and finds a positive cumulative abnormal return of around $10 \%$ after the first year. The positive result is confined to smaller companies, with market capitalisation of less than R3,5bn, whilst large companies experience a marginally negative cumulative abnormal return. The results also show that those companies which made BEE announcements prior to May 2005 ('first-movers') did somewhat worse than those who followed. Finally, the results were found to be consistent for companies making further BEE related announcements, although the cumulative abnormal returns were lower at around $6 \%$.
\end{abstract}

\section{INTRODUCTION}

In the wake of the first democratic election in 1994, South Africa's ANC government, under Nelson Mandela, set about correcting many of the imbalances of apartheid. The Truth and Reconciliation Commission, co-chaired by Archbishop Desmond Tutu, sought healing, reconciliation and limited compensation to the victims of past atrocities. But, to a large extent, redress for the economic injustices, such as job reservation for whites, so called 'Bantu education' and limited property rights, was to be achieved through a transformation agenda under the banner of Black Economic Empowerment (BEE) which included voluntary sector "charters" followed by legislation.

From 1994 and earlier, South African companies faced significant pressure to comply with the broader principles of empowerment, as wealth inequality ${ }^{1}$ remains amongst the highest in the world. The land re-possessions and failed economy of neighbouring Zimbabwe signaled one possible scenario from lack of action, whilst the hasty but flawed Russian privatization process presented another. $^{2}$

\footnotetext{
"Gordon Institute of Business Science, University of Pretoria, Illovo Johannesburg 2196. This material is based on work financially supported by the National Research Foundation. Email:wardm@gibs.co.za
}

${ }^{1}$ The World Bank's 2008 World Development Indicators rank South Africa amongst the worst in terms of unequal income distribution, with a GINI coefficient close to 6 .

${ }^{2}$ The Russian privatization, after communism was discredited, was the biggest and quickest in history. It saw 140m Russians receiving vouchers which they could swap for shares, sell or invest. With the exception of certain "crown jewels", ownership of the entire state-owned industry was essentially given away to the populous. Those with a better understanding of the process were able to exploit the system, with a resulting concentration of
Mining rights, once owned in perpetuity by mining companies, became subject to a five year review and renewal process. The release of the draft mining charter in October 2002, which first proposed such changes, caused a severe negative reaction in the share prices of SA mining companies. Industry-wide empowerment charters followed, with both positive and negative implications. Any company requiring certain licenses or wanting to conduct business with the State needed to ensure that its own suppliers were BEE compliant, thereby "propelling empowerment into the far reaches of the economy" (Businessmap Foundation 2005). Many commentators argued that BEE compliance would improve a firm's access to customers and enhance revenues and profits.

To begin with no formal or legal mechanism compelled businesses to participate in BEE. In practice however, concluding a BEE transaction was an "unavoidable imperative for many enterprises" (Businessmap Foundation, 2005). Over time the voluntary sector charters acquired various levels of legal status, culminating in the Broad-Based Black Empowerment Act of 2003.

By way of illustration, the voluntary financial services charter, unveiled in 2003, set a target of $25 \%$ black ownership by 2010 . Furthermore, $33 \%$ of the members of a company's board were required to be black. The charter stipulated six key areas of economic empowerment which were to be monitored in terms of a scorecard by the financial institutions themselves:

1. business ownership and control;

2. recruiting and development of human resources;

wealth which now has 28 million Russians $(20 \%)$ earning less than US $\$ 30$ a month, whilst Forbes magazine reported Moscow as having 26 dollar billionaires, more than any other city including New York. (Business Day, $31^{\text {st }}$ October 2005). 
3. procurement and enterprise development;

4. access to financial services;

5. empowerment financing; and

6. corporate social investment.

In 2004, to address the issue of ownership and control, some $240 \mathrm{BEE}$ transactions with a value of more than R62bn were concluded (Businessmap Foundation, 2005). By 2008 Moody's investor services estimated the total value of BEE deals at R200bn (Business Day, 2008). Since direct control could not usually be purchased by poorly resourced black investors, complex financial structures were often required. These involved (for example) loans which would be refunded over time by the dividends of the newly purchased shares, share option schemes or new shares issued at (sometimes) deep discounts.

BEE related transactions carried both positive and negative signals. Companies with appropriate BEE credentials could benefit from lucrative government contracts (for example) but may have acquired their BEE status with complex and expensive shareholder deals. This research examines the long-term stockmarket reaction to announcements by JSE listed companies relating to black empowerment transactions affecting ownership. The null hypothesis is that no short or long term abnormal returns exist.

\section{LITERATURE}

In evaluating the broader impact of BEE in redressing past economic injustices, Van der Berg, Burger, Burger, Louw \& Yu (2005) note that little has been done in the area of poverty alleviation other than expanded social grants. With regard to education, whilst equality in State funding for teachers at all schools exists, teacher skills, governance and resource availability at black schools remains problematic (Van der Berg, 2005; 2006). Bhorat \& Hinks (2005) note that employment creation since 1994 has been dismal, with young black entrants to the labour force particularly heavily impacted (Makgetla, 2006). The proportion of black workers in low income groups has actually increased since 2000 (Valodia, Lebani, Skinner \& Devey, 2006) and Altman (2006) shows that the wage gap between 1995 and 2003 has also increased. In the private sector, between 1996 and 2004 the percentage of blacks in senior management declined, largely in favour of coloureds and Asians, and to a lesser extent whites (Makgetla, 2006; Altman, 2006) although a number of researchers do note that the black middle-class has grown significantly post 1994 (Burger, Burger \& Van der Berg, 2003; Van der Berg, 2005; Makgetla, 2006).

In a paper which outlines the history and development of BEE in South Africa, Ponte, Roberts \& Van Sittert (2006) show that black control of JSE listed companies, measured in terms of share of market capitalisation, peaked at $9,6 \%$ in 1999 and dropped to
$5,8 \%$ in 2005 . They ascribe this decline to poorly structured empowerment deals with high gearing and over-priced assets. They also note that "during the BEE period the biggest South African multinationals Old Mutual, SAB, Liberty Life, Anglo-American and de Beers - have localized their headquarters outside South Africa, presumably putting their major assets beyond the reach and recall of the post-apartheid State" (Ponte et al., 2006:46).

Ponte et al. (2006) present three case studies in which they evaluate the effect of BEE in different industries. They note that BEE has effectively saddled black capital with high risk primary sector production assets, whilst "incumbent monopoly capital, under the banner of redistribution" retains control over logistics, distribution, marketing and branding (Ponte et al., 2006:42). They conclude that: "BEE has become a managerial and technocratic process that may thwart the overall objectives of empowerment" and "BEE is now based on such levels of complexity that it implicitly legitimizes 'outsourcing' of its management from government to the private (auditing) sector, thus reinforcing a further weakening of the State and facilitating a next round of 'outsourcing' of previously political and now managerialized functions" (Ponte et al., 2006:1).

Sartorius \& Botha (2008) use content analysis on 72 JSE listed company announcements over the period 1999 - 2005 to determine the extent of ownership transferred through BEE deals and the reasons given for the transactions. They find that only 17 companies report transactions resulting in $25 \%$ or greater black ownership. They also note that the reasons given for the BEE transactions were a mixture, inter alia: 'value creation', 'social responsibility' and 'compliance'.

Jackson, Alessandri \& Black (2005) use an eventstudy approach to measure the impact on share prices of announcements of BEE transactions on a sample of 20 JSE listed companies. Using a market model they estimated betas over the 200 trading days prior to the announcement. Over a 5 day event window they find significant positive cumulative abnormal returns of $1,8 \%$, suggesting that the market rewarded such transactions. In the year following the announcements they find that BEE firms out-performed an equally weighted index by $31 \%$. The authors also note that BEE transactions were completed with an average discount of almost $10 \%$ to the ruling share price of the relevant company. As they themselves note however, their research was limited by a small sample size and may have benefited from a control-portfolio model to eliminate market effects.

Between 1998 and 2005 the percentage of merger and acquisition deals relating to $B E E$ rose from around $10 \%$ to $30 \%$. In their review of Merger and Acquisition activity in South Africa, Ernst \& Young (2005) list BEE as a major driver of acquisition activity, noting that, of 
the 744 deals in 2004, 238 were BEE related. They note that: "BEE deals come at a cost to existing shareholders, whether as a result of being asked to give up a portion of their existing holdings at a discount to market price or as a result of the company funding the structures at below market rates. There is also a cost associated with management time and adviser fees" (Ernst \& Young, 2005:34). They present an analysis of reported costs from a sample 10 companies who engaged in BEE transactions and show that for the acquirer, the economic transaction cost of a BEE deal ranged from a low of $2,2 \%$ of market capitalisation to $4,4 \%$.

On a more positive note, Dawkins \& Ngunjiri (2008) find that corporate social responsibility reporting is higher in the top 100 South African listed companies than the Fortune Global 100 companies. They ascribe this to a greater willingness by South African corporations to convey social responsibility in their disclosure practices, on account of a climate of greater stakeholder awareness.

Cahan \& Van Staden (2008), in a paper which examines the 'oddity' of Value Added Statements (VAS), which occur frequently in South African financial statements, suggest that this is a mechanism to secure legitimacy with labour. The voluntary inclusion of a supplementary VAS shows the distribution of value amongst stakeholder groups. The authors find a significant positive relationship between a company's BEE score ${ }^{3}$ and the existence of a VAS.

In summary, the literature presents contrasting perspectives on the impact of BEE. Only one paper examines the response by shareholders to BEE announcements, but suffers from a small sample (20 transactions) and weak methodology.

\section{METHODOLOGY}

\subsection{Overview}

A standard methodology for event studies has been established over time (see: Brown \& Warner, 1980; Bowman, 1983; Bhana, 1998 and Madura \& Akhigbe, 1995). This methodology is broadly applied in this study, with some differences as discussed below.

\subsection{Population and sample}

The population under consideration for the event study comprised all shares listed on the JSE over the period 1 January 2000 to 31 December 2008. Companies listed on the JSE are required to make announcements to shareholders of any material issues which may impact share prices through the Stock

\footnotetext{
${ }^{3}$ BEE scores are awarded by Empowerdex (an independent empowerment rating agency) on the basis of a BEE audit.
}

Exchange News Service (SENS). SENS is an electronic notice board and information system designed to ensure that price-sensitive announcements can be received timeously and simultaneously by investors and analysts. On an average day around 40 announcements relating to corporate activities are made through SENS.

Using a database containing all SENS announcements, a content search was conducted for all BEE related announcements. Over the period 1 January 2001 to 31 December 2008, a total of 175 different companies made at least one announcement relating to BEE. The first BEE related SENS announcement by each of these companies was selected and reviewed for relevance. Each announcement was examined for potentially confounding events such as trading results or unrelated corporate actions, and such announcements were omitted. A reduced sample of 140 first announcements, free from confounding events, was used in the initial analysis.

The methodology required four years of share price data prior to the announcement date for the estimation of betas and a further 250 trading days after the announcement for the analysis of the abnormal returns. In those instances where there was insufficient data the observations were removed. Finally, since the methodology is particularly sensitive over the long term to any bias in the data, the returns of each share were examined for outliers. A number of thinly traded small company shares were identified and those with a market capitalisation of less than R100m at the event date were removed from the sample. Furthermore, the value of shares traded in the 4 week period around the event date was calculated, and shares in which the value traded was less than $\mathrm{R} 1 \mathrm{~m}$ were removed. The final sample consisted of 118 unique companies.

Following the same approach, a second sample of 'further BEE announcements' was determined. This sample comprised those companies from the first sample which made second (or third, etc.) announcements of a new BEE related transaction in the remainder of the study period. To ensure that these announcements related to new BEE deals, and to avoid confounding issues with the first data set, the further BEE announcements were required to have occurred at least one year after the previous BEE event. The second sample contained 28 observations.

Lyon, Barber \& Tsai (1999) note that the analysis of long-term abnormal returns is "treacherous" (Lyon et al., 1999:165). Therefore, an important consideration for event studies, and particularly for long-term studies, is the choice of benchmark against which abnormal returns are estimated. Many event studies use a market or single parameter CAPM model as the benchmark, but this has been shown to be inadequate. In particular, the CAPM fails to account for expected 
returns on the basis of company size as well as growth versus value (see Fama \& French, 1992, 1993, 1995, 1996, 1998) and in the South African context, a further consideration is 'resource' versus 'non-resource' shares (see Van Rensburg 2001; Van Rensburg \& Robertson 2003a, 2003b). Accordingly, a 12 parameter 'style' model was used to estimate benchmark returns in this study. Following Mordant \& Muller (2003) and Mutooni \& Muller (2007), twelve 'control portfolios' of shares representing the crosssectional factors of size, growth/value and resources/non-resources were created as shown in Table 1.

\section{Table 1: Control portfolios}

\begin{tabular}{llll}
\hline $\begin{array}{l}\text { Control } \\
\text { Portfolio }\end{array}$ & $\begin{array}{l}\text { Resources or } \\
\text { non-resources } \\
\text { company }\end{array}$ & $\begin{array}{l}\text { Value or } \\
\text { growth } \\
\text { company }\end{array}$ & Company size \\
\hline SGN & Non-resources & Growth & Small \\
SGR & Resources & Growth & Small \\
SVN & Non-resources & Value & Small \\
SVR & Resources & Value & Small \\
MGN & Non-resources & Growth & Medium \\
MGR & Resources & Growth & Medium \\
MVN & Non-resources & Value & Medium \\
MVR & Resources & Value & Medium \\
LGN & Non-resources & Growth & Large \\
LGR & Resources & Growth & Large \\
LVN & Non-resources & Value & Large \\
LVR & Resources & Value & Large \\
\hline
\end{tabular}

The classification of these twelve control portfolios was determined as follows:

- A company's size was measured by its market capitalisation. All the companies listed on the JSE were ranked in descending order of market capitalisation and the 40 shares with the largest market capitalisation constituted the large capitalisation control portfolio. This replicated those in the JSE'S ALSI40 Index. Shares, with a market capitalisation ranking between 41 and 100 constituted the medium capitalisation control portfolio, and the remaining shares formed the small capitalisation control portfolio;

- A company was classified as a growth or a value investment in terms of its price-to-earnings ratio. The price-to-earnings ratios were calculated and ranked, after which the median was determined. All companies with price-to-earnings ratios above the median were classified into the growth portfolio and the remainder into the value portfolio;

- The broad JSE sector groupings were used as criteria to decide whether stocks represented a 'resource' share or not. All mining and non-mining resource shares were classified as resources while the rest of the market was classified as nonresources.

Each share listed on the JSE was placed into one of the twelve control portfolios depending on its characteristics. The control portfolios were rebalanced every quarter to ensure that changes in share characteristics (price-to-earnings ratios, market capitalisations, new listings and de-listings) were closely tracked over time. De-listed shares were included up to the date of termination of trading, after which the share price returns of the de-listed companies were assumed to be zero until the end of the quarter. The de-listed shares were excluded from the following quarter's rebalancing of control portfolios. Similarly, the share price returns of newly listed shares were included in the following quarter, when the control portfolios were rebalanced.

Daily equal-weighted indices were constructed for each of the twelve control portfolios using log returns see Equation 1.

$R_{i t}=\log \left[P_{i t} / P_{i t-1}\right]$

where:

$\mathrm{R}_{\mathrm{it}}=$ the equal weighted share return for portfolio $\mathrm{i}$ for day $t$;

and

$P_{i t}=$ the equal weighted share value of portfolio $i$ at the end of day $t$.

Following Mordant \& Muller (2003), beta coefficients were then calculated for each share in the event sample by regressing each share's monthly logfunction share price return over the preceding 48month period against the monthly returns of each of the twelve control portfolios for the matching period. The result was a regression equation (Equation 2) for each selection. An alpha coefficient for each share was also obtained from the regression equation and included in the estimation of expected returns. Alpha and beta parameters for each share in the sample were updated on a rolling monthly basis using prior data.

The control portfolio model measures the expected return of share ${ }_{i}$ in period ${ }_{t}$ as the sum of the sensitivity of share $e_{i}$ to the returns on the twelve control portfolios and a calculated alpha estimate in period $t_{t}$. This is summarised in Equation 2:

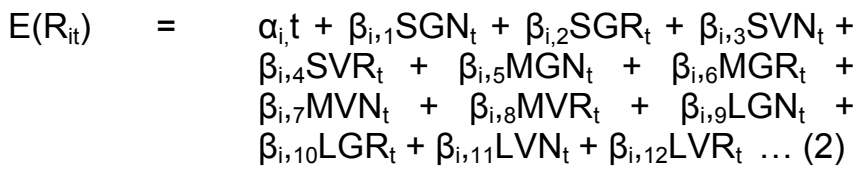

where: 


\begin{tabular}{|c|c|c|}
\hline$E\left(R_{i t}\right)$ & $=$ & $\begin{array}{l}\text { the expected return on security } y_{i} \text { on } \\
\text { day }_{t} ;\end{array}$ \\
\hline$x_{i, t}$ & & $\begin{array}{l}\text { the alpha intercept term of security } \\
\text { on day } \text { di }_{t}\end{array}$ \\
\hline 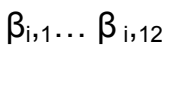 & & $\begin{array}{l}\text { the beta coefficients on } \epsilon \\
\text { control portfolio return; }\end{array}$ \\
\hline
\end{tabular}

$S G N_{t} \ldots S G R_{t}=$ the log-function share price returns on each of the twelve control portfolios set out in Table 1 on day t.

Daily abnormal returns (ARs) were then calculated in terms of Equation 3, and then averaged across the sample for the event analysis.

$$
A R_{\text {it }} \quad=R_{\text {it }}-E\left(R_{i t}\right)
$$

where:

$$
\mathrm{AR}_{\mathrm{it}} \quad=\begin{aligned}
& \text { the abnormal return of } \text { stock }_{i} \text { in } \\
& \text { period }_{t ;}
\end{aligned}
$$

$E\left(R_{i t}\right)=$ the expected share price return of stock $_{i}$ in period determined in terms $_{t}$ of Equation 2;

$\mathrm{R}_{\mathrm{it}} \quad=\quad$ actual return of stock in period $_{t}$

In addition to the control portfolio method for estimating expected returns described above, the single beta CAPM approach was also used to ensure that the results were robust. A single beta for each share in the sample was estimated by regressing the 60 months of return data, prior to the event date, against the returns on the $\mathrm{J} 203$ index. Both results are reported, although greater emphasis is given to the control portfolio method.

Performance over an extended period was calculated by accumulating the average Abnormal Returns to obtain the Cumulative Abnormal Return (CAR) for each share, over the event window period. Observations were equal-weighted, but to investigate whether size was a factor, the sample was ranked by market capitalization and split into two equal groups; 'large' companies and 'not-large' companies. The analysis was repeated for each sub-sample.

To further test the robustness of the results, and to examine the significance of any cross-sectional variables, the analysis was repeated by splitting the sample into two equal groups based on the median event date. The intention was to examine whether BEE deals which were announced in the initial years of BEE differed from those announced later.

Finally, the analysis was repeated for the sample of 28 companies which made 'further BEE announcements' (i.e. second and third BEE related deals).

\subsection{Data}

Data for this study were obtained from the Sharenet database. The JSE's SENS database was used to track name changes, corporate actions and de-listings where relevant. Data was corrected for share splits, consolidations and swaps. For rights issues occurring in the event period, a passive investment strategy was followed, i.e. no rights were taken up; these were allowed to lapse. Survivor bias was eliminated by ensuring all listed shares over the study period were included in the study.

\section{$2.4 \quad$ Hypothesis testing}

Brown \& Warner $(1980,1985)$ present the most commonly used parametric tests to measure significance on abnormal returns from event studies. McWilliams \& McWilliams (2000) present an aggregated z-test for cumulative abnormal returns (CARS); provided these are normally distributed. Sanger \& McConnell (1986), Cowen \& Sergeant (1996) and Corrado (1989) all offer appropriate nonparametric tests. In this study, in addition to the commonly used t-test, a boot-strapping process was used to test ARs and CARs for significance (Noreen, 1989).

Using the daily abnormal returns on each of the shares in the event sample for the three prior years, a bootstrap distribution of one day ARs for each sample was constructed. The abnormal returns over the event period could then be tested against this distribution for significance. This method of significance testing is superior to the t-test in that no assumption is made of normality. Following the same method, boot-strap distributions were constructed for 10 day CARs, against which the 10 day CARs in the event period were tested for significance.

\section{RESULTS}

The results are presented graphically below. Each graph shows the cumulative average abnormal return (CAR) for the relevant (sub) sample of the data on the $y$-axis, with event time commencing at day t-20 and ending on day $t+230$ on the $x$-axis. In each instance, the CAR is shown using both the control portfolio approach to estimate abnormal returns as well as the CAPM single beta model, as a test of robustness. 


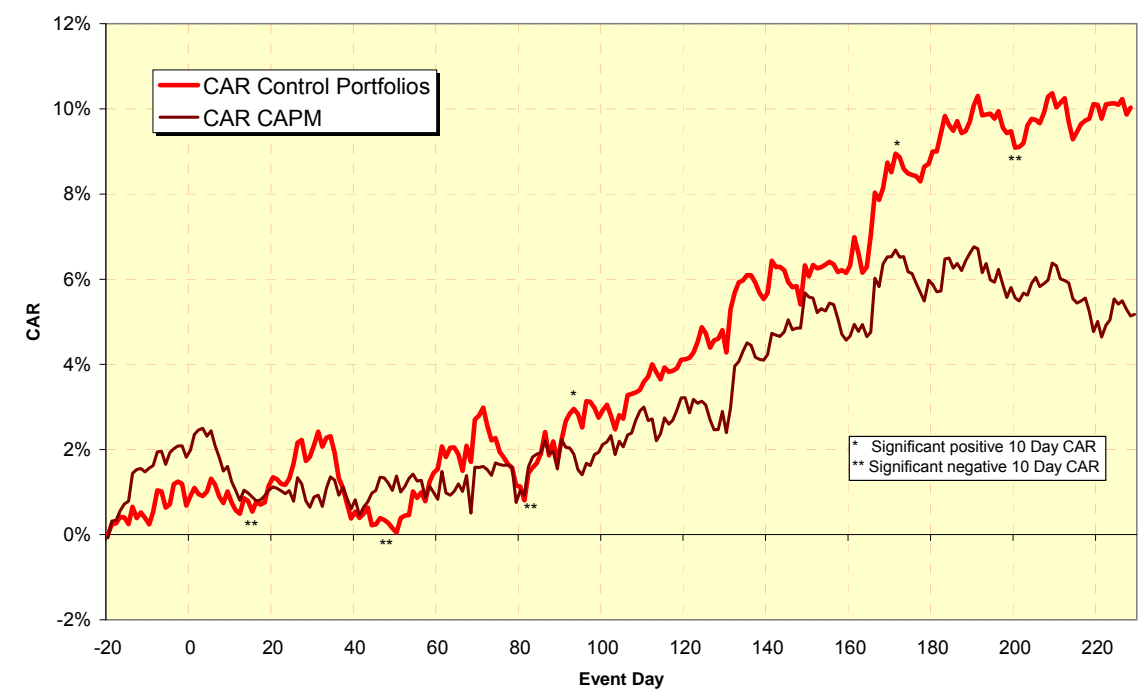

Figure 1: CARs for the full sample $(n=118)$ of first BEE transaction announcements

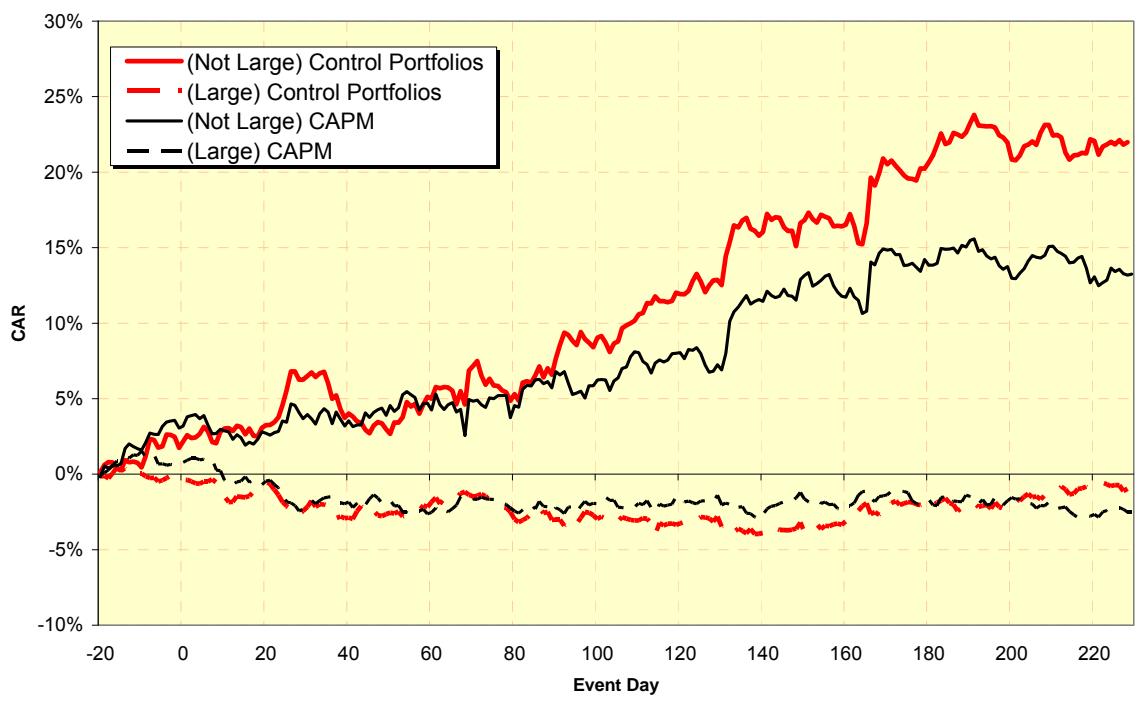

Figure 2: CARs for the sub-samples split in terms of market capitalization

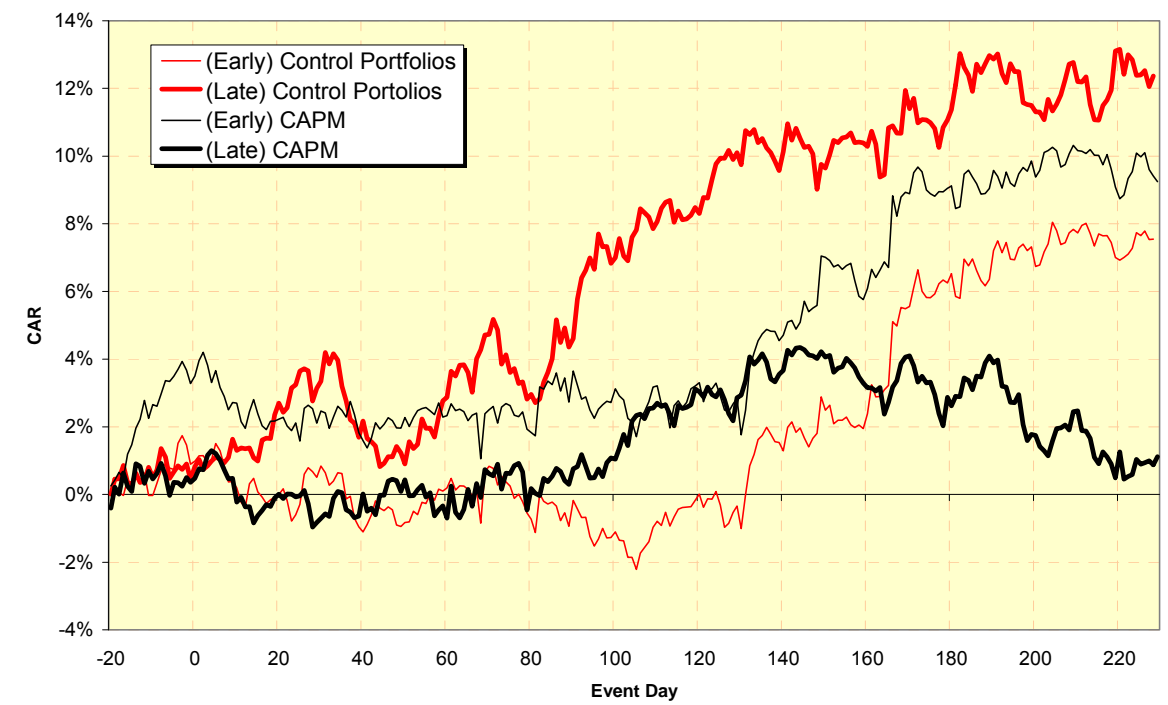

Figure 3: CARs for the sub-samples split in terms of early versus late announcement date 


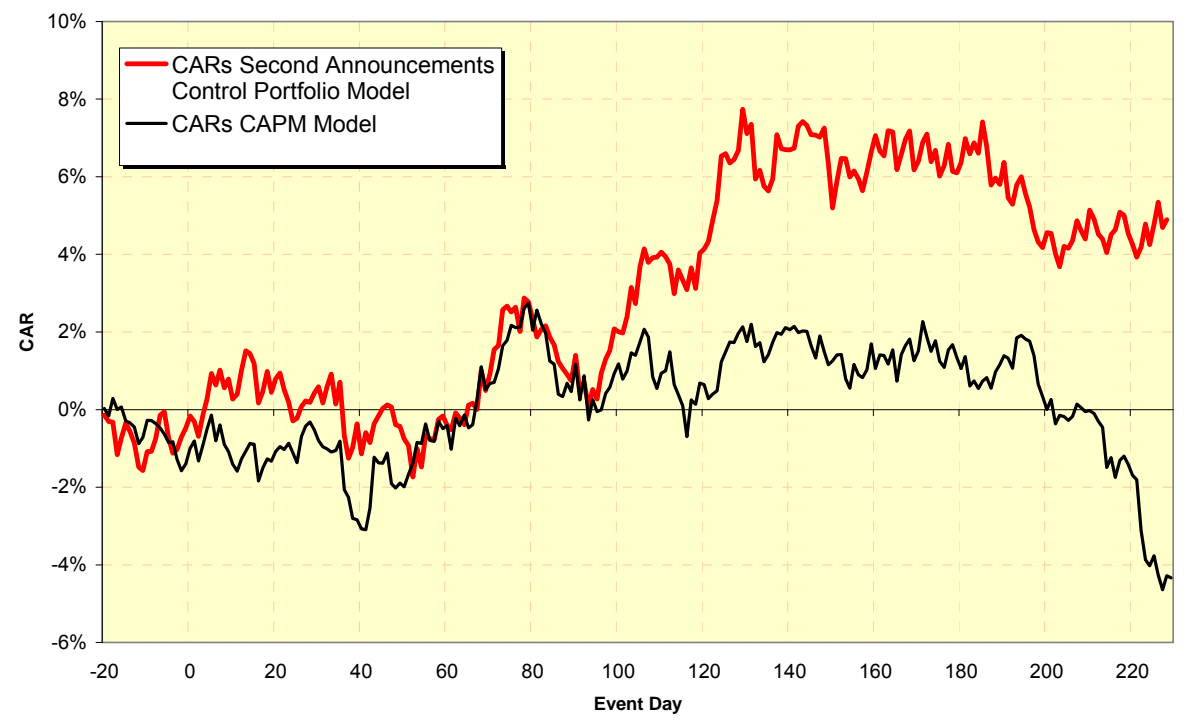

Figure 4: CARs for those companies making further BEE announcements $(n=28)$

In Figure 1, using the full sample of 118 announcements, both methods for estimating abnormal returns show positive cumulative abnormal returns. However, these only commence around day $t+80$. The control-portfolio approach is more sensitive, resulting in a positive CAR of around $10 \%$ towards the end of the event period $(t+230)$.

Figure 2 presents the results for the sample split by market capitalization. Both methods for estimating abnormal returns follow similar trends, but again, the control-portfolio approach is more sensitive. For smaller companies ('not-large') the CARs are strongly positive. The large company sub-sample shows a (marginally) negative CAR.

In Figure 3 the results are shown for the sample split in terms of early versus later (in the sample period) BEE announcements. CARs using the control portfolio benchmark become positive for the 'early' sub-sample only after day $t+140$, whereas those announced later in the period are positive almost immediately, and reach a level of $12 \%$. CARs using the CAPM benchmark show similar but much less definitive results.

Figure 4 shows the results of the 28 companies making second (or further) BEE announcements. As with Figure 1, the CARs are positive, but only from around $t+90$. The level of cumulative abnormal returns for the sample reaches a maximum of around $7 \%$ after $t+120$, using the more sensitive control portfolio approach.

As described above, significance tests were conducted on the ARs and the CARs using both a t-test and a non-parametric boot-strap distribution, which was calculated from out-of-sample data. The results for the $\mathrm{t}-20$ to $\mathrm{t}+20$ event window are reported in Table 2 .
Table 2: Average abnormal returns

\begin{tabular}{cccc}
\hline Event Day & $\begin{array}{c}\text { All } \mathbf{n = 1 1 8} \\
\text { AARs }\end{array}$ & $\begin{array}{c}\text { Bootstrap } \\
\text { Area to the right }\end{array}$ & $\begin{array}{c}\text { t-test } \\
\text { Area to the right }\end{array}$ \\
\hline \multicolumn{4}{c}{ Significantly positive AARs at $5 \%$ level } \\
\hline 69 & $0,98 \%$ & $2,80 \%$ & $0,05 \%$ \\
131 & $0,97 \%$ & $2,80 \%$ & $0,05 \%$ \\
149 & $0,87 \%$ & $3,60 \%$ & $0,17 \%$ \\
166 & $0,94 \%$ & $3,20 \%$ & $0,07 \%$ \\
& & & \\
\multicolumn{4}{c}{ Significantly negative AARs at $5 \%$ level } \\
\hline 28 & $-0,51 \%$ & $96,70 \%$ & $97,30 \%$ \\
36 & $-0,49 \%$ & $96,30 \%$ & $96,86 \%$ \\
87 & $-0,58 \%$ & $97,40 \%$ & $98,62 \%$ \\
89 & $-0,54 \%$ & $96,90 \%$ & $97,93 \%$ \\
130 & $-0,47 \%$ & $95,60 \%$ & $96,43 \%$ \\
213 & $-0,50 \%$ & $96,50 \%$ & $97,12 \%$ \\
\hline
\end{tabular}

As can be seen from Table 2, there are several significant average ARs in the full sample $(n=118)$ over the event window (only those event days significant at a $5 \%$ level using the bootstrap distribution and the ttest are shown). On day $\mathrm{t}-1$ a significant negative average $A R$ is shown. This is likely to be a reflection the market's disapproval of the transaction, and indicates some degree of probable insider trading, since the response precedes the SENS announcements. Significantly negative average ARs follow on days $t+28$ and $t+36$. Thereafter there are significant positive average ARs interspersed with negative ones on several days. 
Table 3: Cumulative average abnormal returns

\begin{tabular}{clcc}
\hline Event Day & $\begin{array}{c}\text { 10day } \\
\text { CARs }\end{array}$ & $\begin{array}{c}\text { Bootstrap } \\
\text { Area to the right }\end{array}$ & $\begin{array}{c}\text { t-test } \\
\text { Area to the right }\end{array}$ \\
\hline \multicolumn{4}{c}{ Significantly positive 10 Day CARs at $5 \%$ level } \\
\hline 91 & $1,84 \%$ & NS $^{*}$ & $3,19 \%$ \\
174 & $2,07 \%$ & NS & $1,61 \%$ \\
& & & \\
& Significantly negative 10 Day CARs at $5 \%$ level \\
\hline 15 & $-0,76 \%$ & $>95 \%$ & $92,87 \%$ \\
46 & $-0,92 \%$ & $>95 \%$ & $95,26 \%$ \\
201 & $-1,10 \%$ & $>95 \%$ & $97,10 \%$ \\
& $-1,09 \%$ & $>95 \%$ & $97,05 \%$ \\
\hline
\end{tabular}

${ }^{*} \mathrm{NS}=$ Not Significant at $5 \%$ level

Table 3 shows the significance tests on cumulative average abnormal returns (CAARs) for the full sample $(n=118)$. Only those event days significant at a $5 \%$ level using either the bootstrap distribution or the t-test are shown, reflecting some differences between the tests. The boot-strap distribution approach showed no positive 10 day CARs over the event window, whereas the t-test showed two positive runs, ending on days 91 and 174. The likely reason for this result is that the distribution of CARs is positively skewed on account of the trend in the data. The $5 \%$ and $95 \%$ cut-off levels on the bootstrap distribution were $-0,75 \%$ and $3,1 \%$, clearly indicating skewness. In the period immediately around the event, $t-20$ to $t+20$ all the CARs were examined, but none were found to be significant. Thereafter, only 10 day CARS were examined on account of the volume of data.

Four significant (negative) 10 day runs of CARs were found over the full event window. One of these ended on $t+15$, confirming the negative reaction to the announcement itself. Thereafter the negative runs appear as 'corrections', occurring after strong and longer positive runs. The significant 10 day CARs are also shown in Figure 1.

\section{CONCLUSIONS}

The study found the JSE to be reasonably inefficient, in that the impact of BEE deals only appears to be incorporated into share prices several days (around $t+80$ ) after the initial public announcement. From event day $t+80$ and for the next 100 trading days the CARs trended positively, reaching a peak cumulative abnormal return of about $10 \%$ on day $t+180$. In the long term, and in general, we find that BEE announcements have a positive effect on share prices and concur with the findings of Jackson et al. (2005).

A close examination of the data showed that this result only applied to smaller companies. When the sample was split around the median market capitalization the positive results held for the smaller half (those with market capitalization < R3,5bn), but large companies had a marginally negative response to BEE announcements. The cumulative abnormal return for smaller companies reached a maximum in excess of $20 \%$ after day $t+180$, indicating strong outperformance. One explanation for this is that smaller companies benefit from being BEE compliant as they are able to increase their turnover and margins on account of their BEE ratings and improved access to State and other contracts. The impact on large companies appears to be marginally negative. This may be because the relative benefits of BEE compliance are small, given that these companies are likely to be already well entrenched. Furthermore, many of the large-cap companies are resource companies, which export commodities in international markets and for whom BEE compliance is a necessary cost of business with little or no benefit.

When the sample is split around early versus late BEE deals, the results showed that whilst both CARs are positive, later (i.e. more recent) deals did much better. Companies who entered into BEE transactions early in the decade (prior to May 2005) i.e. 'first-movers' showed little or no abnormal performance for the first 6 months. Over the following 6 months the cumulative abnormal returns grew strongly to $8 \%$ over the remainder of the event window. Late entrants showed positive abnormal returns from announcement date, reaching a cumulative value of around $12 \%$ over the year. These findings suggest that the market has moved to a more positive view on BEE transactions.

A repeat of the study for those companies which announced second (or additional) BEE deals reflects similar results to the initial sample. The BEE announcement was ultimately positive, but the CARs only start to trend upwards around day $t+90$. Furthermore, these deals were less attractive, achieving CARs of around $6 \%$ at event day $t+140$, somewhat less than the $10 \%$ achieved in the initial sample.

The main finding of this research is that the long-term market response to BEE deals is strongly positive for companies with a market capitalisation of less than $\mathrm{R} 3,5 \mathrm{bn}$, and marginally negative for large companies.

\section{REFERENCES}

Altman M. 2006. Wage determination in South Africa: what do we know? Transformation, 60: 58-89.

Bhana N. 1998. Share price reaction to announcements of equity financing by companies listed on the Johannesburg Stock Exchange. The Investment Analysts Journal, 48: 35-44.

Bhorat H. and Hinks T. 2005. Changing patterns of employment and employer-employee relations in post- 
Apartheid South Africa, paper presented at Stellenbosch University conference on South African Policy Under Democracy: A 10 Year Review, 27-28 October, 2005.

Bowman R. 1983. Understanding and conducting event studies. Journal of Business and Financial Accounting, 10(4): 561-584.

Brown S. and Warner J. 1980. Measuring security price performance. Journal of Financial Economics, 8: 205-258.

Brown S. and Warner J. 1985. Using daily stock returns: The case of event studies. Journal of Financial Economics, 14: 3-31.

Burger R. Burger R. and Van der Berg S. 2003. Emergent black affluence and social mobility, paper presented at TIPS/DPRU Conference, Johannesburg, 8-10 September 2003.

Business Day. 2008. Moodys Ratings. 16 May.

Businessmap Foundation. 2005. Behind the deals. http://www.businessmap.org.za/documents.asp?DID=1 $\underline{277}$, accessed 20 May 2007.

Cahan S. and Van Staden C. 2008. Black economic empowerment, legitimacy and the value added statement: evidence from post-apartheid South Africa. Accounting and Finance, 49(1): 37-58.

Corrado C. 1989. A non parametric test for abnormal security price performance in event studies. Journal of Financial Economics, 23: 385-395.

Cowen A. and Sergeant A. 1996. Trading frequency and event study test specification. Journal of Banking and Finance, 20: 1731-1757.

Dawkins C. and Ngunjiri F. 2008. Corporate social responsibility reporting in South Africa, Journal of Business Communication, 45(3): 286-307

Ernst \& Young (South Africa). 2005. Mergers \& acquisitions: A review of activity. Johannesburg: Ernst \& Young.

Fama E. and French K. 1992. The cross-section of expected stock returns. Journal of Finance, 47(2): 427465.

Fama E. and French K. 1993. Common risk factors in the returns of stocks and bonds. Journal of Financial Economics, 53: 427-465.

Fama E. and French K. 1995. Size and book to market factors in earnings and returns. Journal of Finance, 50: 131-155.
Fama E. and French K. 1996. Multifactor explanations of asset pricing anomalies. Journal of Finance, 51: 5584.

Fama E. and French K. 1998. Value versus growth: The international evidence. Journal of Finance, 53: 1975-1999.

Jackson W. Alessandri T. and Black S. 2005. The price of corporate social responsibility: The case of Black Economic Empowerment transactions in South Africa. Federal Reserve Bank of Atlanta. Working Paper: 2005-29.

Lyon J. Barber B. and Tsai C. 1999. Improved methods for tests of long-run abnormal stock returns. Journal of Finance, 54(1): 165-201.

Madura J. and Akhigbe A. 1995. Influence of economic factors on the valuation effects of debt offerings. Applied Economics, 27: 907-915.

Makgetla N. 2006 BEE and class formation. New Agenda 22: 47-58.

McWilliams T. and McWilliams V. 2000. Another look at theoretical and empirical issues in event study methodology. The Journal of Applied Business Research, 16(3): 1-11.

Mordant N. and Muller C. 2003. Profitability of director's share dealings on the JSE. Investment Analysts Journal, 57: 17-32.

Mutooni R. and Muller C. 2007. Equity style timing. Investment Analyst Journal: 65: 15-24.

Noreen E. 1989. Computer intensive methods for testing hypotheses, John Wiley \& Sons: New York.

Ponte S. Roberts S. and Van Sittert L. 2006. To BEE or not to BEE: South Africa's 'Black Economic Empowerment' (BEE), Corporate governance and the state in the South. Danish Institute for International Studies, Working Paper, 2006/27.

Sanger G. and McConnell J. 1986. Stock exchange listings, firm value and security market efficiency: the impact of NASDAQ. Journal of Financial and Quantitative Analysis, 21: 1-25.

Sartorius K. and Botha G. 2008. Black economic empowerment ownership initiatives: A Johannesburg Stock Exchange perspective. Development Southern Africa, 25(4): 437- 453.

Valodia I. Lebani L. Skinner C. and Devey R. 2006. Low-waged and informal employment in South Africa. Transformation, 60: 90-126. 
Van der Berg S. 2005. Apartheid's enduring legacy: Inequalities in education, paper presented at Stellenbosch University conference on South African policy under democracy: A 10 year review, 27-28 October, 2005.

Van der Berg S. 2006. How effective are poor schools? Poverty and educational outcomes in South Africa. University of Stellenbosch Stellenbosch Economic Working Papers, 06/06.

Van der Berg S. Burger R. Burger R. Louw M. and Yu D. 2005. Trends in poverty and inequality since the political transition. University of Stellenbosch Stellenbosch Economic Working Papers: 01/05.

Van Rensberg P. 2001. A decomposition of stylebased risk on the JSE. Investment Analysts Journal, 54: 45-60.

Van Rensburg P. and Robertson M. 2003a. Style characteristics and the cross-section of JSE returns. Investments Analysts Journal, 57: 1-10.

Van Rensburg P. and Robertson M. 2003b. Size, price to earnings and beta on the JSE. Investments Analysts Journal, 58: 1-11. 